This is the peer-reviewed version of the following article: Leifeld, Philip and Volker Schneider (2012): Information Exchange in Policy Networks. American Journal of Political Science 53(3): 731-744, which has been published in final form at http://dx.doi.org/10.1111/j.1540-5907.2011.00580.x. This article may be used for non-commercial purposes in accordance with Wiley Terms and Conditions for Self-Archiving.

\title{
Information Exchange in Policy Networks
}

\author{
Philip Leifeld Volker Schneider
}

\begin{abstract}
Information exchange in policy networks is usually attributed to preference similarity, influence reputation, social trust and institutional actor roles. We suggest that political opportunity structures and transaction costs play another crucial role and estimate a rich statistical network model on tie formation in the German toxic chemicals policy domain. The results indicate that the effect of preference similarity is absorbed by institutional, relational and social opportunity structures. Political actors choose contacts that minimize transaction costs while maximizing outreach and information. We also find that different types of information exchange operate in complementary, but not necessarily congruent, ways.
\end{abstract}

Keywords: Policy Networks, ERGM, Information Exchange, Transaction Cost Theory, Interest Groups

The policy network approach assumes that policy-making is affected by a variety of organized governmental and non-governmental actors (Adam and Kriesi 2007), who maintain relations like information or resource exchange, influence attribution, or common group membership. Policy networks are usually supported by "polycentric" institutional arrangements (Ostrom 2010) facilitating collaboration and information exchange in a long-term pespective as a kind of " $2^{\text {nd }}$ order economization" (Williamson 2000).

The question how policy networks operate has provoked a substantial number of policy network studies over the course of the last 30 years. Some of the more recent analyses have tried to assess the reasons why political actors establish contacts to some actors but not to others. Particularly ideology (Henry, Lubell, and McCoy 2011; Laumann, Tam, Heinz et al. 1992), preference similarity on political issues (Carpenter, Esterling, and Lazer 2004; Henry, Lubell, and McCoy 2011; König and Bräuninger 1998; Weible and Sabatier 2005; Zafonte and Sabatier 1998), preference dissimilarity (Stokman and Zeggelink 1996; Stokman and Berveling 1998), functional or institutional interdependence (König and Bräuninger 1998; Zafonte and Sabatier 1998), social trust (Carpenter, Esterling, and Lazer 2004; Henry, Lubell, and McCoy 2011; Berardo and Scholz 2010) and

The authors wish to thank Martin F. Hellwig, Christoph Engel, Andreas Glöckner, Ben Domingue, Beaugitte Laurent and four anonymous reviewers for helpful comments and the Max Planck International Research Network on Aging (MaxNetAging) for financial support.

The replication dataset can be downloaded from http://hdl.handle.net/1902.1/17004. The R source code is available in the supporting information online. 
perceived influence (Stokman and Zeggelink 1996; Stokman and Berveling 1998; Weible and Sabatier 2005) have been found to be drivers of tie formation in policy networks.

In contrast to some of the above-mentioned studies, we argue that preference similarity does not predict tie formation in policy networks sufficiently well. Instead, we posit that institutional, relational and social opportunity structures exert a strong influence on the communication between actors. Establishing contacts is apparently not trivial, so actors have to rely on institutionalized venues like policy-related committees, and make use of already existing channels of communication, among other strategies that minimize informational costs and maximize the credibility of the information they obtain. We subsume the arguments of preference similarity and opportunity structures under a broader theory of "transaction cost politics" (North 1990) applied to policy networks.

Moreover, tie formation is qualified by the type of information exchange under scrutiny. This point has been neglected by other studies conducted so far. Scientific or technical information exchange, on the one hand, and political or strategic information exchange, on the other hand, may serve quite different purposes. This qualification can also explain why some empirical studies find a positive correlation between preference similarity and tie probability, while others suggest a negative association.

We examine these points by analyzing political and technical information exchange in the policy domain of toxic chemicals regulation in Germany in the 1980s. Previous work on this policy network by the authors (Schneider 1988; Schneider and Leifeld 2009) has revealed that actors who occupy central positions in the information exchange network also maintain policy positions closer to the final policy outcome. In the light of this policyrelevant finding, it is interesting to know what drives centrality in the communication network, or more broadly, what determines whether two organizations actually exchange information or not. The primary goal is to find a model that explains policy network formation sufficiently well. To the best of our knowledge, this is the first time that all of the presumably relevant hypotheses are included in a single model and that dyadic dependence is explicitly taken into account.

Our paper is structured as follows: first, we set out our argument about opportunity structures and transaction costs and derive testable hypotheses. The next section introduces the policy domain under scrutiny, the data collection process, our variables, and the methodology of exponential random graph models that we employ. We will present the results of our analysis and discuss the model fit. A conclusion puts the results into perspective and suggests further theoretical and empirical pathways.

\section{Opportunity structures and transaction costs}

Contact-making in policy networks is beneficial for several reasons. It serves to gather information, disseminate information (and thus exert influence), and team up with allies against political opponents. Yet, at the same time, actors cannot simply maintain information exchange relations with all other actors who are presumably relevant. Establishing contacts is expensive in terms of labor, time and money. Resources spent on contact-making cannot be spent on other activities which may have a higher priority. Agents weigh the costs and benefits of establishing a contact. This observation is in line with more general models of network formation (Bala and Goyal 2000).

Political actors try to reduce transaction costs by making use of "opportunity structures". The notion of opportunity structures emerged between 1930 and 1960 as a soci- 
ological concept (Merton 1995) emphasizing "differential access to opportunities". Later it diffused to social movement research (Kitschelt 1986) and institutional analysis (Knill 2001) in political science. As early as in 1973, Laumann and Pappi (1973) used the idea of opportunity structures in a twofold perspective differentiating between an institutional and a relational view. In such a perspective, we conceive of opportunity structures as pre-existing or institutionalized venues where actors can communicate without incurring significant costs.

In a "transaction cost politics" perspective (North 1990), institutionalized forms of exchange and collaboration can be more efficient due to lower transaction costs in the long run (Williamson 1991). This view is also supported by associational theories of interest intermediation, such as neo-corporatism, where institutionalized participation in policy-making via specialized committees and forums is regarded as a distinct form of governance beside communities, states and markets (Streeck and Schmitter 1985). Along these lines, Schneider, Scholz, Lubell et al. (2003) view networks as public goods because institutionalized relations help to promote cooperative solutions to policy problems precisely by overcoming transaction costs.

\section{Policy committees as institutionalized venues}

In policy committees at the national and supranational level, relevant governmental and non-governmental actors participate in collective policy deliberation, decision-making and implementation. Recently, such arrangements have also been discussed as "collaborative institutions" (Lubell, Henry, and McCoy 2010) or "collaborative governance" (Ansell and Gash 2008). They are important institutional opportunity structures for communication in policy making. Our institutional opportunity structure hypothesis implies that policy makers and interest groups try to use institutionalized access to policy-making committees to acquire "cheap" contacts in the pursuit of minimizing costs while maximizing outreach and information. Being connected anyway by shared membership in policy committees means that communication is facilitated by low transaction costs. Actors literally go the path of least resistance in order to keep transaction costs at a low level: the more institutionalized venues there are, the more likely is a communication tie (as conjectured but not explicitly tested by König and Bräuninger 1998: 448), all else being equal. We therefore devise the following hypothesis:

\section{Hypothesis 1: Policy committees}

The more common policy committees two actors take part in, the more likely they are to exchange information.

\section{Existing social relations}

Transaction costs may also be reduced by informal relational opportunity structures. They are not necessarily institutionalized. A second test of the opportunity structure hypothesis can be achieved when considering the different types of information that exist and that can be exchanged by actors.

As will be demonstrated below, two complementary logics of information exchange are at work, which rest on two different types of communication between agents: political/strategic and technical/scientific information exchange. Both types of information are on a continuum, but we assume that it is possible to distinguish between them by employing standardized questions, albeit with some "noise". 
Actors use already existing channels to reduce transaction costs. If actor A sends scientific information to actor B anyhow, there are virtually no costs associated with sending further information, such as strategic advice, and vice-versa.

\section{Hypothesis 2 a: Other communication channels \\ If an actor sends political/strategic information to another actor, it is more likely also to send technical/scientific information to the other actor, and vice versa.}

Similarly, an ego that obtains information from an alter can be expected to reciprocate this information exchange tie because the channel exists anyway and does not cause any new costs. Reciprocity of edges is also a relational opportunity structure.

\section{Hypothesis 2 b: Reciprocity}

If an actor receives information from another actor, it is more likely also to send information to this actor.

\section{Influence of third parties on information exchange}

Institutional opportunity structures and pre-existing relational information channels are only two obvious ways to avoid transaction costs. A strongly related social opportunity structure is the existence of third parties and hence social trust.

In interpersonal networks, approaching strangers is more costly than approaching friends of friends. Common acquaintances help to reduce the uncertainty about the quality of the alter. Interorganizational relations work in a similar way. Actors need common "friends" to reduce uncertainty about the quality of their contact (cf. Berardo and Scholz 2010). Coordinating with another organization is more promising the more shared partners exist. The number of allies who trust an organization is a good indicator of its quality, both in terms of its information (for an information-centric perspective, see Carpenter, Esterling, and Lazer 2004) and in terms of being a powerful ally. Common neighborhood clearly matters. As a consequence, actors are more likely to trust information from another organization if it is in the same coalition. At the meso-level, this mechanism results in self-reinforcing coalitions (Henry, Lubell, and McCoy 2011; Sabatier and Weible 2007). The number of shared partners is also related to the concept of "bonding" structures as transitive triads increase ego's trust in alter (Berardo and Scholz 2010). ${ }^{1}$

But the argument expands beyond quality. Relying on one's contacts to establish new ties lowers the costs of searching for new contacts and deciding whether they are worth the effort. Trusting others is more efficient. We therefore include a transitivity-related term in our model which checks whether directed two-paths between two actors positively affect their likelihood of establishing a direct tie.

\section{Hypothesis 3: Third parties}

The more shared partners two actors have, the more likely they are to establish an information exchange link.

\footnotetext{
${ }^{1}$ See the supporting information for more details about transitivity versus shared partners.
} 


\section{Perceived influence and formal decision-making power}

In a transaction cost perspective, perceived influence of a potential alter is a sign of high quality, either in terms of its information potential or as a powerful ally. Opting for such contacts increases the benefits of information exchange. Perceived influence serves as a search heuristic. Connecting to presumably influential agents is the best bet if the quality of an alter is otherwise unknown.

Weible and Sabatier (2005) find a moderate effect of influence attribution on policy coordination and advice-seeking even when holding preference similarity constant. Their study on California Marine Protected Area Policy reveals that "in technical, complex policy subsystems with influential organizational affiliations that control resources, actors have to get some advice/information and coordinate somewhat with influential affiliations - irrespective of beliefs" (Weible and Sabatier 2005: 471). This interpretation follows resource dependence theory (Pfeffer and Salancik 1978), which states that organizations have to establish contacts to well-resourced organizations to maintain their survival in a world of scarce resources. Actors seek alliances with those who are in control of formal decision-making power or informal, but extensive, access to relevant decision makers. Hojnacki (1997) provides evidence for the effect of perceived influence on alliance-seeking: "when organizations perceived to be 'pivotal' to success are members of an alliance [...], the benefits of coalition appear substantial" (Hojnacki 1997: 61). We test for the effect of influence attribution by including the following hypothesis:

\section{Hypothesis 4 a: Perceived influence}

The greater an actor perceives the influence of another actor, the more likely the actor is to establish an information exchange tie to this potential contact.

Evidently, this hypothesis bears the danger of misspecifying the direction of causality. Does ego choose alter because it perceives alter to be influential? Or does ego rate alter as being influential because overemphasizing the influence of one's contacts boosts one's own reputation? In order to avoid this potential pitfall, we additionally model the institutional influence rather than perceived influence as a driving factor of information exchange. The assumption underlying the following hypothesis is that governmental actors - in the narrow sense, e. g., federal ministries and administrative agencies - are by definition influential because they can exert formal decision-making power.

\section{Hypothesis 4 b: Governmental access \\ Governmental actors have disproportionately many incoming information ex- change ties.}

Thereby, interest groups are likely to submit scientific information to the government in order to increase the chance that their views and opinions are codified into law. This argument is resonated by the literature on lobbying. In the model of Austen-Smith and Wright (1992) and in many theories of interest intermediation (for an overview, see van Waarden 1992), interest groups send information to governmental actors. The literature on policy network formation largely supports the governmental access hypothesis (Carpenter, Esterling, and Lazer 2004; König and Bräuninger 1998).

In addition to this lobbying perspective, decision-makers actively acquire technical knowledge from scientific actors and think tanks in order to increase the quality of their decisions or simply to obtain justification of their decisions (Sabatier 1987: 650). 


\section{Interest group homophily}

In order to maximize the benefits of communication, interest groups are especially likely to connect to other interest groups. We can expect this pattern for two reasons.

First, information exchange serves to coordinate activities in pursuit of a common goal. Such a goal is nowhere else as pronounced as in lobbying groups because their very motivation is to change (or retain) the status quo. In other words, interest groups are more likely than other actors to seek alliances because their payoff from cooperating with others is higher. At the same time, interest groups are particularly attractive allies because their intrinsic motivation to attain policy goals is higher than the intrinsic motivation of other actors like, for example, scientific organizations.

Second, interest groups seek to convince their opponents, so they send them technical information about the appropriate policy design. Quite obviously, other interest groups are - if decision-makers are controlled for - the primary target of belief manipulation via technical information because they are at the core of the adversarial coalition (Sabatier and Weible 2007). The two mechanisms result in mutual attachment between interest groups (in network terms "homophily", cf. McPherson, Smith-Lovin, and Cook 2001).

\section{Hypothesis 5: Interest group homophily \\ Interest groups are particularly likely to exchange information with other in- terest groups.}

\section{Two complementary logics of information exchange}

Most of the literature on policy network formation stresses that preference similarity is key to understanding information exchange patterns. We therefore examine the effect of preference similarity and use it as a baseline for our model. Moreover, there are two apparently contradictory mechanisms of preference similarity. They can be resolved by taking into account the type of information that is exchanged. We subsume preference similarity under the cost-benefit model of policy network formation presented above.

The majority of studies finds that information exchange is driven by similar preferences (Carpenter, Esterling, and Lazer 2004; Henry, Lubell, and McCoy 2011; Huckfeldt and Sprague 1987; König and Bräuninger 1998; Sabatier and Weible 2007; Weible and Sabatier 2005; Zafonte and Sabatier 1998). Few others suggest that actors seek to establish links to agents with dissimilar preferences (cf. Kollman 1997). This view is reflected in the policy maximization model of Stokman and Zeggelink (1996) and Stokman and Berveling (1998) and the competitive lobbying model of Austen-Smith and Wright (1992). A third theoretical possibility is that actors initially have no opinion and are convinced by other actors. How can these seemingly contrary hypotheses be reconciled?

Political actors weigh the costs and benefits of establishing a tie. In the first perspective, coordination with like-minded actors is advantageous because coalitions are more powerful in the political process than individual agents. This is in line with the prediction of the Advocacy Coalition Framework (Sabatier and Weible 2007) that coordination takes place inside coalitions, but not between them. Here, the contents of institutional communication is political or strategic information. Shared strategies can be conceived of as a power resource (König and Bräuninger 1998). Contact-making is beneficial because coalition-building is instrumental for becoming a policy winner (Baumgartner and Jones 1991). Obviously, contacts with a similar ideology have the highest utility, which renders preference similarity a special case of the theory outlined above. 
In the second perspective, actors try to "convince" adversarial organizations of the optimal policy design and thus their own ideal points by establishing "access relations". The type of information being transmitted here is rather technical or scientific and includes details about how the policy at issue could be designed. It contains knowledge about the causes and consequences of a complex problem, policy goal priorities, and technical policy advice, often generated by scientific organizations in the first place and sent to interest groups or governmental actors. Both types of information are on a continuum, but we assume that it is possible to distinguish between them by employing standardized questions, albeit with some "noise". In order to take into account these two logics of information exchange, we estimate two separate models.

Yet, access relations are only possible because the supply of technical information is met by a corresponding demand of such information at the opposite side of a mutual exchange relation. This touches upon the third theoretical option presented above. There is a need for reliable and timely information. Technical information is an important resource in the struggle against complexity and uncertainty (Heclo 1978). Actors will turn to other agents whom they deem well-informed, and these agents are not necessarily opponents. Therefore, we expect the effect of preference similarity to be much less pronounced in the technical/scientific information exchange network.

If the above propositions hold true, we should expect actors in the latter network to draw their information primarily from scientific organizations because they are technically knowledgeable, and policy analyses originating from science are often used to justify one's own policy beliefs (Sabatier 1987). We include a control variable for scientific organizations as information senders. According to our distinction, scientific actors maintain many outgoing information ties in the scientific information exchange network. This should not be the case when it comes to political and strategic information.

\section{Data collection and methodology}

The previous sections have set out a theory of information exchange between policy actors which incorporates opportunity structures and preference similarity as two concurrent drivers of policy network formation. We have compiled a list of testable hypotheses which are implied by the theory. They shall be tested with a dataset on toxic chemicals regulation in Germany in the 1980s collected by one of the authors (Schneider 1988). This section will introduce the case of toxic chemicals policy-making and describe the data collection process.

\section{The toxic chemicals problem}

After World War II, the production of chemicals increased to an unprecedented level. Approximately 100,000 different chemical substances were traded on the global market. Many of these chemicals were evidently extremely dangerous for human health and the environment, sometimes in the form of insidious diseases or after long-term contact. At the beginning of the 1970s, most industrialized countries adopted the view that a passive treatment of these toxic substances was no longer affordable. They initiated chemicals control programs and testing procedures for chemical substances.

In Germany, a legislative process was started mainly upon the initiative of the OECD and the European Community at the end of the 1970s. The effort culminated in the adoption of a law for the protection against dangerous substances (ChemG) in 1980 . 
However, this law was restricted to the control of newly produced chemicals without considering toxic substances already on the market. This restriction was intended by the chemical industry because it feared fatal economic consequences if control obligations were extended to existing chemicals. The chemical industry association (VCI) took a lead position in this process because it possessed the representational monopoly of economic and industrial interests in this policy domain, and these were in turn major employers and investors on the global market. The chemical industry was not only a growth sector; to a certain degree, it also promised a future-proof development due to its structural closeness to genetic research, biotechnology and related industrial branches.

\section{Selection of actors}

As the main point of reference of this system of policy actors was the chemicals problem and its direct and indirect effects, it was possible to define a set of interested actors. As far as direct influences in the life cycle of a chemical are concerned, occupational safety, health and environmental interests were potentially affected by the toxicity of the substances. Moreover, a set of governmental actors was bound to react to the politicization of the problem by these societal actors. It is therefore quite easy to derive the following set of actors on theoretical and institutional grounds: the state, parties/the parliament, organized interests (capital, labor, environment and consumers) and finally actors from science and technology.

Methods from elite research were applied to conduct a proper specification of the boundaries of the network (cf. Laumann, Marsden, and Prensky 1983). This task was not negligible because the results of a network analysis critically depend on the valid and reliable selection of actors. The positional approach served to compile a list of all possible organizations from institutional sectors that were potentially affected by the problem of toxic chemicals. The names of these organizations were collected from relevant handbooks about public organizations and the list of lobbyists in the German parliament. At the second stage of the selection procedure, press archives, lists of participants of relevant events, and protocols and documents of relevant agencies and ministries were surveyed to confirm or discard the actual participation of organizations, and some new actors were added. This second stage is called the decision approach. The resulting list contained 90 organizations that were asked to submit annual reports, position papers, press releases and other relevant documents. On the basis of these documents and a number of expert interviews, 39 organizations were selected and asked to fill out a standardized questionnaire in the winter of 1984/1985, following the approach of Laumann and Knoke (1987) and Laumann and Pappi (1973). Eight more actors were named by the interviewees. The response rate was $85 \%$ (40 out of the 47 actors). To obtain a complete influence core from this actor set, only those 30 actors were retained who were cited as being influential by at least one of the other actors. This final list of actors is composed of eleven governmental actors (among them six federal ministries), three parties, seven organized interest groups, six scientific/research organizations, and three international organizations. Further details about the actors and the data collection process are provided by Schneider (1988).

The set of 30 actors is somewhat smaller than the datasets used in some of the other articles. However, the careful data collection procedure ensures a high quality of the data in terms of reliability and validity. Since the two networks to be modeled are directed and we concentrate on edges as the unit of analysis, there are $n^{2}-n=870$ observations 
which are partly dependent on each other, so the real number of observations might be smaller than 870 .

\section{Measurement and variables}

The two network relations of interest are political/strategic and scientific/technical information exchange. The political/strategic information exchange network was collected by setting the following task: ${ }^{2}$

"Please list the names of all organizations with which you regularly exchange information about affairs related to chemicals control."

This network does not contain information about who sends information to whom, but it is still directed because actors indicate whom they perceive to be information exchange partners. The technical/scientific information exchange network was collected by asking respondents the following questions:

"In the decision process on the chemicals law, scientific and technical information was of central importance.

a) From which of the organizations mentioned on the list does your organization usually obtain scientific and technical information?

b) To which of the organizations does your organization deliver such information?"

These two separate pieces of information about sending and receiving technical/scientific information were combined in a single network matrix $\mathbf{T}$ by multiplying the entries of the sender matrix $\mathbf{S}$ with the entries of the transpose of the receiver matrix $\mathbf{R}$ (i. e., the Hadamard product). In other words, only when both sender and receiver indicated a common tie, was it coded as 1 , otherwise as 0 . The result is a confirmed network:

$$
\mathbf{T}:=\mathbf{S} \odot \mathbf{R}^{T}
$$

Preference similarity was measured by identifying six core policy topics relevant in the decision process: self-regulation, the scope of the reform, the control procedure, the timing of the control mechanism, intensity of control, and the treatment of chemicals already being traded on the market (for more details, see the original study). For all actors, agreement or disagreement with each issue was coded either as +1 (agreement), 0 (neutrality), or -1 (disagreement). The resulting variables $i \ldots n$ were used to construct a dissimilarity matrix by calculating the Euclidean distance $d$ between each pair of actors $p$ and $q$ :

$$
d(p, q)=\sqrt{\sum_{i=1}^{n}\left(p_{i}-q_{i}\right)^{2}}
$$

The dissimilarity matrix was converted into a similarity matrix by subtracting each dissimilarity value from the maximum dissimilarity value:

$$
s(p, q)=\max (d)-d(p, q)
$$

\footnotetext{
${ }^{2}$ The original questionnaire was in German. The questions have been translated for this article.
} 
The resulting matrix of preference similarities between actors can be interpreted as an undirected, weighted network, which can be subsequently used as an edge covariate in a statistical network model.

Perceived influence was collected as a binary, directed network matrix with the row actor indicating what column actors it perceived as influential.

Membership in policy committees was collected from the various documents surveyed during the selection process and recorded as binary attribute variables in a data matrix M. A square co-occurrence matrix $\mathbf{C}$ was generated, indicating which pairs of actors attended how many committees together:

$$
\mathbf{C}:=\mathbf{M} \cdot \mathbf{M}^{T}
$$

\section{Methodology and model specification}

The purpose of this article is twofold: on the one hand, a statistical network model will be employed to test the hypotheses set out above. On the other hand, the goal is to model the information exchange behavior of political actors as adequately as possible, so we are eventually able to reproduce the tie formation process using simulations.

As mentioned earlier on, networks show complex dependencies between ties, resulting in matrix autocorrelation. In other words, the error terms in a simple OLS regression would be correlated across observations, standard errors would be too small, and $p$ values too optimistic. We therefore model the dependencies directly as a social network and draw on the family of exponential random graph models (ERGM), or p* models, described by Robins, Pattison, Kalish et al. (2007) and Robins, Snijders, Wang et al. (2007) and implemented in the statnet package (Handcock, Hunter, Butts et al. 2003) for the statistical computing environment $\mathrm{R}$ ( $\mathrm{R}$ Development Core Team 2009). ERGMs are an attempt at modeling the tie structure of a whole network in bottom-up fashion by describing the network in terms of endogenous structural properties like cycles, clustering or density, and covariates, which can take the form of nodal attributes (e.g., actor type) and edge covariates (i. e., other relations).

The general form of exponential random graphs can be written as

$$
\operatorname{Pr}(\mathbf{Y}=y)=\left(\frac{1}{\kappa}\right) \exp \left\{\sum_{A} \eta_{A} g_{A}(y)\right\}
$$

with $y$ representing a tie in the network $\mathbf{Y}, \kappa$ being a normalizing constant to ensure that the probability scales to $1, g_{A}(\mathbf{y})$ representing the model terms listed in table 1 ( $A$ is the index of the model terms), and $\eta_{A}$ being the coefficients of the model terms. Examples for possible $g$ statistics include the number of edges in the network, the number of edges from interest groups to other interest groups, the number of policy committees co-attended by tied actors, or the number of shared partners of connected actors (cf. Goodreau, Kitts, and Morris 2009). $\eta$ reflects the empirical impact of a $g$ statistic on the observed network $\mathbf{Y}$. In order to model our two information exchange networks $\mathbf{Y}_{1}$ and $\mathbf{Y}_{2}$, we estimate a dyadic dependence model with the model terms listed in table 1.

The model is fitted via Markov Chain Monte Carlo Maximum Likelihood Estimation (MCMC MLE). The estimated coefficients can be interpreted like in a logit regression model. The dependent variable is the log odds of establishing a network tie. Coefficients are interpreted as log-odds ratios conditional on the rest of the network. 


\begin{tabular}{|c|c|c|}
\hline$L(y)$ & $\begin{array}{l}\text { a term containing the number of edges in the graph, } \\
\sum_{i<j} y_{i j}\end{array}$ & \\
\hline$C(y)$ & $\begin{array}{l}\text { an undirected, weighted edge covariate representing the } \\
\text { number of common committee memberships as defined } \\
\text { in equation } 4\end{array}$ & $\mathrm{H}_{1}$ \\
\hline$O(y)$ & $\begin{array}{l}\text { a directed, binary edge covariate representing the other } \\
\text { communication type not represented by Y (scienti- } \\
\text { fic/technical or political/strategic communication) }\end{array}$ & $\mathrm{H}_{2 \mathrm{a}}$ \\
\hline$R(y)$ & $\begin{array}{l}\text { a statistic capturing the propensity of ties to be recip- } \\
\text { rocated }\end{array}$ & $\mathrm{H}_{2 \mathrm{~b}}$ \\
\hline$v\left(y, \theta_{1}\right)$ & $\begin{array}{l}\text { GWESP, the geometrically weighted edge-wise shared } \\
\text { partner statistic with parameter } \theta_{1} \text {; see Hunter }(2007) \\
\text { for details; we use a rather low value of } \theta_{1}=0.1 \text { to avoid } \\
\text { model degeneracy }\end{array}$ & $\mathrm{H}_{3}$ \\
\hline$w\left(y, \theta_{2}\right)$ & $\begin{array}{l}\text { GWDSP, the geometrically weighted dyad-wise shared } \\
\text { partner statistic with parameter } \theta_{2}=0.1\end{array}$ & $\mathrm{H}_{3}$ \\
\hline$I A(y)$ & $\begin{array}{l}\text { a directed, binary edge covariate representing influence } \\
\text { attribution }\end{array}$ & $\mathrm{H}_{4 \mathrm{a}}$ \\
\hline$I F_{\text {gov }}(y)$ & $\begin{array}{l}\text { a statistic representing ties where the target is a govern- } \\
\text { mental actor }\end{array}$ & $\mathrm{H}_{4 \mathrm{~b}}$ \\
\hline$U_{i g}(y)$ & $\begin{array}{l}\text { a nodal attribute mixing statistic representing ties where } \\
\text { both the source and the target are interest groups }\end{array}$ & $\mathrm{H}_{5}$ \\
\hline$P S(y)$ & $\begin{array}{l}\text { an undirected, weighted edge covariate representing } \\
\text { preference similarity as calculated by equation } 3\end{array}$ & $\mathrm{C}_{1}$ \\
\hline$O F_{s c i}(y)$ & $\begin{array}{l}\text { a statistic representing ties where the source is a scien- } \\
\text { tific actor }\end{array}$ & $\mathrm{C}_{2}$ \\
\hline
\end{tabular}

Table 1: Model terms and their affiliated hypotheses or control variables

\section{Results and discussion}

Table 2 shows the estimation results for four models. The first two are models of political/strategic information exchange, and the last two of technical/scientific information exchange. The edge term $L(y)$ is comparable to the constant in other statistical models. The first and the third model are limited to estimating the effect of preference similarity on information exchange.

In the case of political/strategic information, tie formation is indeed positively associated with preference similarity, while there is no such association in the case of technical/scientific information. The former observation is in accordance with the policy maximization model (Stokman and Zeggelink 1996) and the Advocacy Coalition Framework (Sabatier and Weible 2007), which posit that strategic information is exchanged primarily among allies. The fact that there is no significant effect in the second case indicates that the association between preferences and technical information exchange might be somewhat more complex. Technical information is not merely used to influence the opponent; this effect seems to be neutralized by the demand for information from trustworthy sources (cf. Heclo 1978; Carpenter, Esterling, and Lazer 2004). 


\begin{tabular}{|c|c|c|c|c|c|}
\hline & & Model 1 & Model 2 & Model 3 & Model 4 \\
\hline$L(y)$ & Edges & $\begin{array}{c}-0.87^{* * *} \\
(0.17)\end{array}$ & $\begin{array}{c}-3.63^{* * *} \\
(0.19)\end{array}$ & $\begin{array}{c}-2.50^{* * *} \\
(0.30)\end{array}$ & $\begin{array}{c}-5.86^{* * *} \\
(0.31)\end{array}$ \\
\hline$P S(y)$ & Preference similarity & $\begin{array}{c}0.18^{* *} \\
(0.06)\end{array}$ & $\begin{array}{c}0.07 \\
(0.07)\end{array}$ & $\begin{array}{c}-0.02 \\
(0.11)\end{array}$ & $\begin{array}{c}-0.05 \\
(0.11)\end{array}$ \\
\hline$I F_{\text {gov }}(y)$ & Governmental alter & & $\begin{array}{l}0.53^{* * *} \\
(0.06)\end{array}$ & & $\begin{array}{l}0.41^{* * *} \\
(0.07)\end{array}$ \\
\hline$O F_{s c i}(y)$ & Scientific ego & & $\begin{array}{c}0.05 \\
(0.09)\end{array}$ & & $\begin{array}{l}1.51^{* * *} \\
(0.10)\end{array}$ \\
\hline$C(y)$ & Common committees & & $\begin{array}{l}0.31^{* * *} \\
(0.01)\end{array}$ & & $\begin{array}{l}0.16^{* * *} \\
(0.01)\end{array}$ \\
\hline$O(y)$ & Scientific communication & & $\begin{array}{l}3.12^{\text {*** }} \\
(0.38)\end{array}$ & & \\
\hline$O(y)$ & Political communication & & & & $\begin{array}{c}2.75^{* * *} \\
(0.06)\end{array}$ \\
\hline$U_{i g}(y)$ & Interest group homophily & & $\begin{array}{l}1.18^{* * *} \\
(0.12)\end{array}$ & & $\begin{array}{c}1.01^{* *} \\
(0.32)\end{array}$ \\
\hline$I A(y)$ & Influence attribution & & $\begin{array}{l}0.84^{* * *} \\
(0.07)\end{array}$ & & $\begin{array}{c}0.47^{* * *} \\
(0.07)\end{array}$ \\
\hline$v\left(y, \theta_{1}\right)$ & GWESP & & $\begin{array}{l}1.26^{* * *} \\
(0.03)\end{array}$ & & $\begin{array}{l}0.43^{* * *} \\
(0.04)\end{array}$ \\
\hline$w\left(y, \theta_{2}\right)$ & GWDSP & & $\begin{array}{c}-0.15^{* * *} \\
(0.02)\end{array}$ & & $\begin{array}{c}-0.23^{* * *} \\
(0.02)\end{array}$ \\
\hline$R(y)$ & Reciprocity & & $\begin{array}{l}0.82^{* * *} \\
(0.06)\end{array}$ & & $\begin{array}{l}1.86^{* * *} \\
(0.15)\end{array}$ \\
\hline & $\mathrm{AIC}$ & 1161.59 & 853.58 & 456.09 & 314.48 \\
\hline & $\mathrm{BIC}$ & 1171.13 & 906.03 & 465.62 & 366.93 \\
\hline & Log Likelihood & -578.80 & -415.79 & -226.04 & -146.24 \\
\hline
\end{tabular}

MCMC MLE. ${ }^{* * *} p<0.001,{ }^{* *} p<0.01,{ }^{*} p<0.05,{ }^{\circ} p<0.1$

Table 2: Exponential random graph model 
If we take any other variable into account, even the positive effect of model 1 disappears. Preference similarity is absorbed by other factors, which are captured by models 2 and 4. Our argument is that actors use institutional, social and relational opportunity structures to establish contacts without incurring significant transaction costs, rather than merely looking for actors that provide a good match. A test of these claims is possible when preference similarity is held constant and the additional effect of opportunity structures is estimated. All three kinds of opportunity structures, as captured by common membership in policy committees, $C(y)$, other social relations, $O(y)$, reciprocity, $R(y)$, and third-party influence, $v\left(y, \theta_{1}\right)$, are strong predictors of tie formation with all six coefficients being highly significant and positive (hypotheses 1, $2 \mathrm{a}, 2 \mathrm{~b}$ and 3). Holding other factors constant, shared access to one additional common policy committee increases the odds of establishing a tie by $36 \%$ in the political/strategic and $17 \%$ in the technical/scientific information exchange network, with a mean number of 1.99 shared committees per dyad. ${ }^{3}$

If two organizations exchange one type of information, they are also much more likely to exchange the other kind of information because the transmission channels exist anyway. The effect of existing communication channels is considerably larger than the other coefficients, but a word of caution is in order when interpreting this result: the measurement of political/strategic information exchange is rather crude, implying that the two types of information exchange are presumably not as clearly separated as they could be, and the two relations might actually contribute less to each other than suggested by the coefficients. However, including existing communication channels does not confound the model; omitting them does not significantly alter the other coefficients. Moreover, the fact that scientific organizations, $O F_{s c i}(y)$, are significant senders of technical/scientific information but not political or strategic information indicates that two separate logics of communication are indeed at work and can be meaningfully distinguished. In the technical communication network, scientific or technical organizations are almost four times as likely to establish an outgoing tie as other organizations, all else being equal.

Like other communication types, reciprocity is a relational opportunity structure. Political and strategic information flows from ego to alter are more than twice as likely if such flows also exist from alter to ego, and ties are more than five times as likely if reverse ties exist in the technical and scientific information exchange network.

Transitivity effects of third parties can be clearly demonstrated as well. The geometrically weighted edge-wise shared partner distribution (GWESP) and the geometrically weighted dyad-wise shared partner distribution (GWDSP) can be interpreted together (Hunter 2007). The GWESP statistic essentially captures whether those actors who are tied are more likely than pure chance to have multiple transitive shared partners. GWDSP captures the propensity of any dyad (whether connected or unconnected) to have multiple transitive shared partners, which is a baseline effect of shared partners in the network. GWESP is interpreted on top of that once dyad-wise shared partners have been controlled for. GWESP and GWDSP have a geometric character, i. e., the number of shared partners per dyad is weighted by $\theta_{1}=\theta_{2}=0.1$. This rather low parameter value puts more emphasis on dyads with few shared partners: dyads with one shared partner are not particularly likely to have a second shared partner, and so on. Increasing the parameter value would slowly decrease the model fit and convergence.

\footnotetext{
${ }^{3}$ The supporting material provides further summary statistics and several alternative model specifications in addition to the source code for replication and the list of actors and committees.
} 
The GWESP statistic is positive and highly significant in both networks, indicating that social trust effects are at work. Connected dyads are indeed likely to have approximately one or two transitive shared partners. GWDSP is significant and negative, i. e., there are generally fewer unconnected dyads with shared partners than predicted by chance. As Baumgartner and Leech (1996: 532) note in their critique of Austen-Smith and Wright (1996), there is a "social nature" of lobbying. Actors rely on others in order to reduce transaction costs when finding allies or sources of information (Carpenter, Esterling, and Lazer 2004; Henry, Lubell, and McCoy 2011). The effect of social opportunity structures is stronger in the case of political and strategic information exchange, presumably because alliance-building requires more trust than establishing access relations to decision-makers or adversarial coalitions.

In general, our findings corroborate and extend the conclusions drawn by Lubell, Schneider, Scholz et al. (2002). Opportunity structures that help to overcome transaction costs boost the emergence of cooperative ties. In addition to institutional and individual factors, social and relational structures play another critical role in promoting coordination. While Lubell, Schneider, Scholz et al. (2002) provide evidence for opportunity structures at the local, individual level, our analysis suggests that policy-making in national-level policy domains works in a similar way.

Beside using opportunity structures to decrease transaction costs, organizations also maximize the benefits of communication by selecting alters by their perceived and factual influence. Actors are $60 \%$ more likely to send technical or scientific information to actors whom they perceive to be particularly influential compared to actors whom they do not rate as particularly influential, even when controlling for the institutional role of the target node. Influence attribution, $I A(y)$, is even more important for alliance-building (Weible and Sabatier 2005): the odds of establishing a tie are increased by $132 \%$.

As is the case with some other variables, we cannot fully rule out that causality may be bi-directional. Nonetheless, omitting any of these variables does not alter the models significantly. Furthermore, we can provide additional evidence for the influencemaximizing behavior of political actors. The positively significant coefficients of the governmental alter effect, $I F_{\text {gov }}(y)$, demonstrate that agents opt for contacts with formal, institutional power (Austen-Smith and Wright 1992; König and Bräuninger 1998).

ERGMs require careful model selection because the same effect can often be reproduced by different network statistics. In an alternative model specification, we have examined whether actors choose others based on the betweenness centrality of the contact. In short, betweenness centrality captures how many shortest paths an actor is involved in, and is therefore a measure of information control (Freeman 1979). Indeed, the model term is highly significant, which is an additional indicator that actors try to maximize outreach to influential actors, but the additional term does not substantially improve the model fit.

Finally, interest groups are especially likely to contact other interest groups. If both actors of a dyad are interest groups, this roughly triples the odds of political or technical information exchange. Although the result is roughly the same for both networks, the mechanism is probably different: in the former case, other interest groups serve as allies, while actors may additionally try to convince their opponents using technical information in the latter model (cf. Sabatier and Weible 2007). In both cases, however, information is a critical power resource that is shared among interest groups with similar preferences (König and Bräuninger 1998). 


\section{Goodness-of-fit diagnostics}
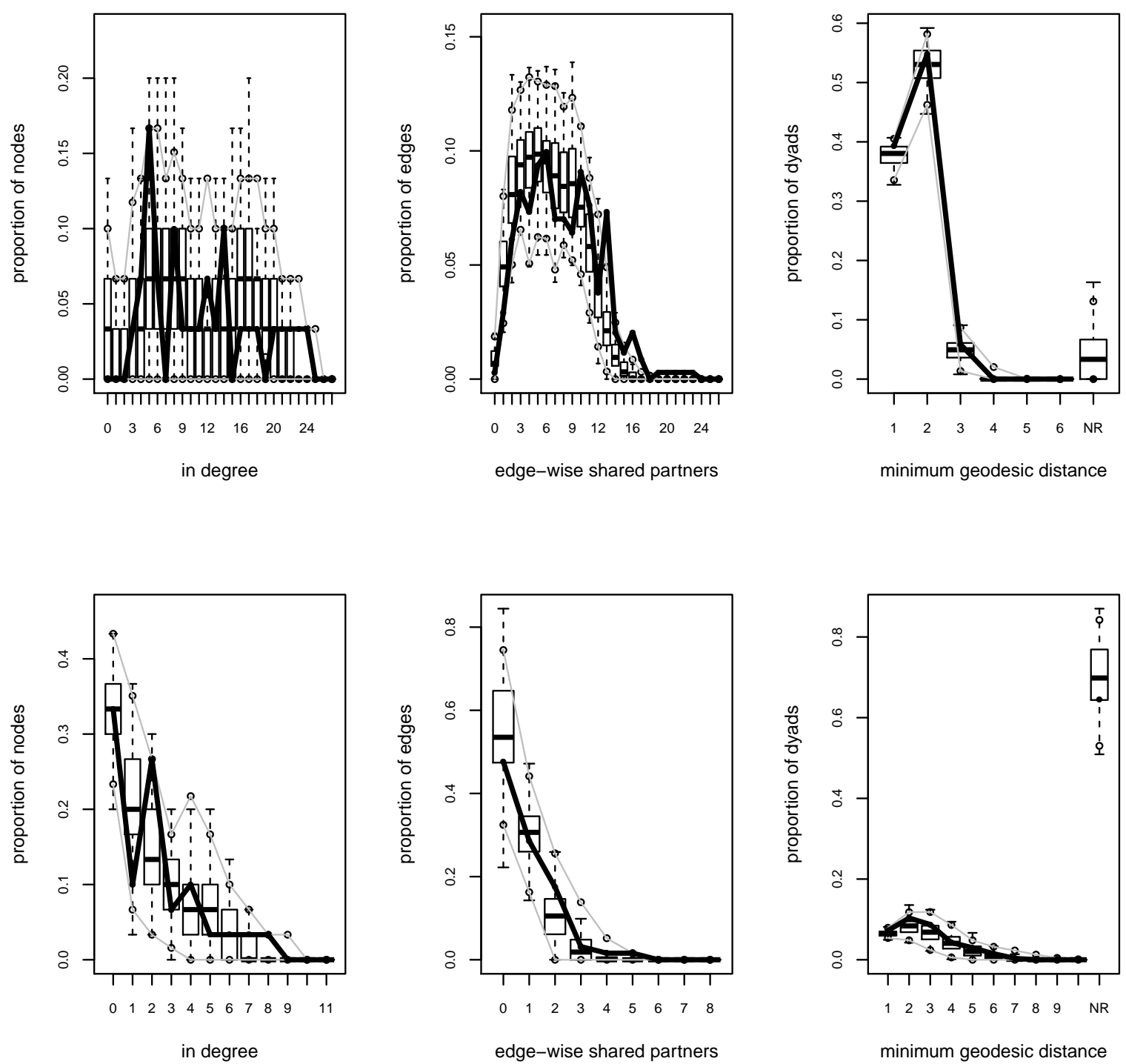

Figure 1: Goodness of fit of the political information exchange model (upper row) and the technical information exchange network (lower row) 


\section{Goodness-of-fit assessment}

As stated at the outset of this article, our primary goal is to find an appropriate model of information exchange. Obviously, this should entail assessing the goodness of fit of our model by simulating new networks from our coefficients. Simulating 100 networks from each of the two complete models shows that the simulated networks are indistinguishable from the original networks by eyeballing them. To support this claim, figure 1 plots three well-known network statistics of the original network (the thick black line) and the 100 simulated networks (the box plots): indegree, minimum geodesic distance, and edge-wise shared partners (for details, see Hunter, Goodreau, and Handcock 2008).

The indegree distribution of the original political network takes a zig-zag curve which can be hardly caught by a parametric model. However, the model is not terribly off the mark. Only indegrees of five, which seem to be quite common in the network, are strongly underrepresented by the model. Nevertheless, adding a network statistic for indegrees of five would certainly mean overfitting the model because there is no guidance in the literature why actors should have five incoming ties, even more so given the much lower frequencies of its neighboring indegrees four and six. The indegree distribution of the technical network exhibits similar variation, but the simulated distributions seem to represent the original network quite well if we consider the overall picture. The other two statistics, minimum geodesic distance and edge-wise shared partners, perform extremely well, with the case of zero edge-wise shared partners being slightly overrepresented by the second model.

Overall, the estimated models fit the data very well and seem to capture most of the variation. All three simulated graph statistics predict the original networks with high accuracy. This is a noteworthy finding because we seem to have incorporated all relevant factors contributing to network formation. Such an undertaking is especially difficult in policy-related applications because many layers of complexity are added by different rationales of actors, institutional roles and constraints, voters, media discourses, etc.

\section{Conclusion}

First and foremost, our analysis has revealed the effect of opportunity structures on tie formation in policy networks. Political organizations take transaction costs into account when considering whom to approach. When actors choose potential interaction partners because they are important in attaining policy-related goals, they also consider if these potential exchange partners are easy to reach. Our finding suggests that politics is not merely power-driven, but also resource-dependent. This bears some interesting policy implications: if the state is interested in balancing organized interests in order not to be captured, it may want to promote civil society groups that cannot afford to take part in the inner circle of sectoral politics. Otherwise, one coalition might become more influential in the political process because its members are well connected, and this coalition might bias political outcomes into their desired direction. This is precisely what happened in the case of German toxic chemicals regulation in the early 1980s (cf. Schneider 1988 for details). This normative approach is not new; it is well-known under the label sponsored pluralism (cf. van Waarden 1992). However, subsidizing organized interests selectively to keep up the balance may have negative welfare implications as well. Economic scrutiny may show whether political gains of a balanced interest group population outweigh efficiency losses due to the subsidies. 
Second, we have assembled a rather rich model of policy network formation. The model fits the data very well, and we are confident that we have contributed to the advancement of the literature on policy networks by providing a baseline model for potential replications in other policy sectors or other contexts. After all, any policy network study can only be a case study (cf. Baumgartner and Leech 1996: 531), and other policy networks might operate quite differently due to other institutional contexts, so this is certainly a worthwhile endeavor. Technological advances like the rise of electronic communication may nowadays affect the way political organizations interact, rendering the necessity of reducing transaction costs via policy committees meaningless.

Moreover, the kind of transaction cost politics outlined here may be a specific characteristic of the German context and similar European political systems which follow a corporatist and consensual tradition. In these regimes, non-majoritarian institutions, such as institutionalized policy committees, are implemented in order to overcome transaction costs (Gehring and Kerler 2008; Majone 2001). These differences between political systems presumably translate into divergent patterns of regulatory policy-making, which would suggest that institutional opportunity structures are less central in the United States or other majoritarian or "adversarial" systems (Jasanoff 2005; Schneider 1985; Vogel 1987).

Toxic chemicals regulation is a rather technical and scientific policy sector. There is universal dependence on others' expertise in technical issue networks due to uncertainty "men collectively wondering what to do" (Heclo 1978). For this reason, regulatory agencies maximize reputation and minimize risk by relying on external information (Moffitt 2010; Carpenter 2002), which may have led to a policy-making style that relies on policy committees in the first place (cf. Jasanoff 2005). We expect that actors find other institutional, relational or social opportunity structures in their pursuit of minimizing the costs of political and strategic information exchange in less technical policy domains.

Third and finally, we have suggested that there is not one single way how a policy network operates. On the contrary, the exchange of technical information differs from strategic information in some respects. Previous studies on tie formation in policy networks tended to ignore this possibility, and information exchange was treated as a homogeneous phenomenon. Nonetheless, the main effects are consistent across the two relations; only institutional roles and preference similarity show different patterns. Reviewing the relevant theoretical literature has, in spite of this, suggested that the two types of relations partly differ in their rationales, but not in their consequences for tie formation patterns. For instance, technical information is often exchanged with allies because they try to establish a common frame of reference (a cooperative relation). At the same time, technical information is also exchanged with opponents, but this time in order to alter their views on optimal policy design (a conflictual relation). Thus the overall effect of preference (dis)similarity cannot be discerned simply by measuring technical information exchange, and the effect cannot be separated from strategic information exchange. We therefore propose that future policy network analyses should take these strategic uses of information into account when collecting data on information exchange between organizations. 


\section{References}

Adam, Silke, and Hanspeter Kriesi. 2007. "The Network Approach." In Theories of the Policy Process, ed. Paul A. Sabatier. Boulder, CO: Westview Press, 129-154.

Ansell, Chris, and Alison Gash. 2008. "Collaborative Governance in Theory and Practice." Journal of Public Administration Research and Theory 18: 543-571.

Austen-Smith, David, and John R. Wright. 1992. "Competitive Lobbying for a Legislator's Vote." Social Choice and Welfare 9: 229-257.

Austen-Smith, David, and John R. Wright. 1996. "Theory and Evidence for Counteractive Lobbying." American Journal of Political Science 40: 543-564.

Bala, Venkatesh, and Sanjeev Goyal. 2000. "A Noncooperative Model of Network Formation." Econometrica 68: 1181-1229.

Baumgartner, Frank R., and Bryan D. Jones. 1991. "Agenda Dynamics and Policy Subsystems." The Journal of Politics 53: 1044-1074.

Baumgartner, Frank R., and Beth L. Leech. 1996. "The Multiple Ambiguities of 'Counteractive Lobbying'." American Journal of Political Science 40: 521-542.

Berardo, Ramiro, and John T. Scholz. 2010. "Self-Organizing Policy Networks: Risk, Partner Selection, and Cooperation in Estuaries." American Journal of Political Science 54: 632-649.

Carpenter, Daniel P. 2002. "Groups, the Media, Agency Waiting Costs, and FDA Drug Approval." American Journal of Political Science 46: 490-505.

Carpenter, Daniel P., Kevin M. Esterling, and David M.J. Lazer. 2004. "Friends, Brokers, and Transitivity: Who Informs whom in Washington Politics?" The Journal of Politics 66: $224-246$.

Freeman, Linton C. 1979. "Centrality in Social Networks: Conceptual Clarification." Social Networks 1: 215-239.

Gehring, Thomas, and Michael Kerler. 2008. "Institutional Stimulation of Deliberative Decision-Making: Division of Labour, Deliberative Legitimacy and Technical Regulation in the European Single Market." Journal of Common Market Studies 46: 10011023.

Goodreau, Steven M., James A. Kitts, and Martina Morris. 2009. "Birds of a Feather, or Friend of a Friend? Using Exponential Random Graph Models to Investigate Adolescent Social Networks." Demography 46: 103-125.

Handcock, Mark S., David R. Hunter, Carter T. Butts, Steven M. Goodreau, and Martina Morris. 2003. statnet: Software Tools for the Statistical Modeling of Network Data. Seattle, WA. http://statnetproject.org (accessed February 16, 2011).

Heclo, Hugh. 1978. "Issue Networks and the Executive Establishment." In The New American Political System, ed. Anthony King. Washington, D.C.: American Enterprise Institute, $87-124$. 
Henry, Adam Douglas, Mark Lubell, and Michael McCoy. 2011. "Belief Systems and Social Capital as Drivers of Policy Network Structure: The Case of California Regional Planning." Journal of Public Administration Research and Theory 39: 361-383.

Hojnacki, Marie. 1997. "Interest Groups' Decisions to Join Alliances or Work Alone." American Journal of Political Science 41: 61-87.

Huckfeldt, Robert, and John Sprague. 1987. "Networks in Context: The Social Flow of Political Information." The American Political Science Review 81: 1197-1216.

Hunter, David R. 2007. "Curved Exponential Family Models for Social Networks." Social Networks 29: 216-230.

Hunter, David R., Steven M. Goodreau, and Mark S. Handcock. 2008. "Goodness of Fit of Social Network Models." Journal of the American Statistical Association 103: $248-258$.

Jasanoff, Sheila. 2005. Designs on Nature: Science and Democracy in Europe and the United States. Princeton: Princeton University Press.

Kitschelt, Herbert P. 1986. "Political Opportunity Structures and Political Protest: AntiNuclear Movements in Four Democracies." British Journal of Political Science 16: $57-85$.

Knill, Christoph. 2001. The Europeanisation of National Administrations: Patterns of Institutional Change and Persistence. Cambridge: Cambridge University Press.

Kollman, Ken. 1997. "Inviting Friends to Lobby: Interest Groups, Ideological Bias, and Congressional Committees." American Journal of Political Science 41: 519-544.

König, Thomas, and Thomas Bräuninger. 1998. "The Formation of Policy Networks: Preferences, Institutions and Actors' Choice of Information and Exchange Relations." Journal of Theoretical Politics 10: 445-471.

Laumann, Edward O., and David Knoke. 1987. The Organizational State: Social Choice in National Policy Domains. Madison: University of Wisconsin Press.

Laumann, Edward O., Peter V. Marsden, and David Prensky. 1983. "The Boundary Specification Problem in Network Analysis." In Applied Network Analysis: A Methodological Introduction, eds. Ronald S. Burt and Michael J. Minor. London: Sage Publications, $18-34$.

Laumann, Edward O., and Franz Urban Pappi. 1973. "New Directions in the Study of Community Elites." American Sociological Review 38: 212-230.

Laumann, Edward O., Tony Tam, John P. Heinz, Robert L. Nelson, and Robert H. Salisbury. 1992. "The Social Organization of the Washington Establishment during the first Reagan Administration." In The Political Consequences of Social Networks, vol. 4 of Research in Politics and Society. A Research Annual, eds. Gwen Moore and J. Allen Whitt. Greenwich, CT: JAI Press, 161-188.

Lubell, Mark, Adam Douglas Henry, and Michael McCoy. 2010. "Collaborative Institutions in an Ecology of Games." American Journal of Political Science 54: 287-300. 
Lubell, Mark, Mark Schneider, John T. Scholz, and Mihriye Mete. 2002. "Watershed Partnerships and the Emergence of Collective Action Institutions." American Journal of Political Science 46: 148-163.

Majone, Giandomenico. 2001. "Nonmajoritarian Institutions and the Limits of Democratic Governance: A Political Transaction-Cost Approach." Journal of Institutional and Theoretical Economics 157: 57-78.

McPherson, Miller, Lynn Smith-Lovin, and James M. Cook. 2001. "Birds of a Feather: Homophily in Social Networks." Annual Review of Sociology 27: 415-444.

Merton, Robert K. 1995. On Social Structure and Science, chap. 13. Chicago: University of Chicago Press, 153-161.

Moffitt, Susan L. 2010. "Promoting Agency Reputation through Public Advice: Advisory Committee Use in the FDA." Journal of Politics 72: 880-893.

North, Douglass C. 1990. "A Transaction Cost Theory of Politics." Journal of Theoretical Politics 2: 355-367.

Ostrom, Elinor. 2010. "Beyond Markets and States: Polycentric Governance of Complex Economic Systems." American Economic Review 100: 641-672.

Pfeffer, Jeffrey, and Gerald R. Salancik. 1978. The External Control of Organizations: A Resource Dependence Perspective. New York: Harper \& Row.

R Development Core Team. 2009. R: A Language and Environment for Statistical Computing. R Foundation for Statistical Computing, Vienna, Austria. http: //www.R-project.org (accessed February 16, 2011).

Robins, Garry, Philippa Pattison, Yuval Kalish, and Dean Lusher. 2007. "An Introduction to Exponential Random Graph (p*) Models for Social Networks." Social Networks 29: 173-191.

Robins, Garry, Tom A.B. Snijders, Peng Wang, Mark Handcock, and Philippa Pattison. 2007. "Recent Developments in Exponential Random Graph (p*) Models for Social Networks." Social Networks 29: 192-215.

Sabatier, Paul A. 1987. "Knowledge, Policy-Oriented Learning, and Policy Change: An Advocacy Coalition Framework." Science Communication 8: 649-692.

Sabatier, Paul A., and Cristopher M. Weible. 2007. "The Advocacy Coalition Framework." In Theories of the Policy Process, ed. Paul A. Sabatier. Boulder, CO: Westview Press, 189-220.

Schneider, Mark, John T. Scholz, Mark Lubell, Denisa Mindruta, and Matthew Edwardsen. 2003. "Building Consensual Institutions: Networks and the National Estuary Program." American Journal of Political Science 47: 143-158.

Schneider, Volker. 1985. "Corporatist and Pluralist Patterns of Policy-Making for Chemicals Control: A Comparison between West Germany and the USA." In Organized Interests and the State. Studies in Meso-Corporatism, ed. Alan Cawson. London: Sage Publications, 174-194. 
Schneider, Volker. 1988. Politiknetzwerke der Chemikalienkontrolle: Eine Analyse einer transnationalen Politikentwicklung. New York/Berlin: de Gruyter.

Schneider, Volker, and Philip Leifeld. 2009. "Überzeugungssysteme, Diskursnetzwerke und politische Kommunikation: Ein zweiter Blick auf die deutsche Chemikalienkontrolle der 1980er Jahre." In Politiknetzwerke. Modelle, Anwendungen und Visualisierungen, eds. Volker Schneider, Frank Janning, Philip Leifeld, and Thomas Malang. Wiesbaden: VS Verlag für Sozialwissenschaften, 139-158.

Stokman, Frans N., and Jaco Berveling. 1998. "Dynamic Modeling of Policy Networks in Amsterdam." Journal of Theoretical Politics 10: 577-601.

Stokman, Frans N., and Evelien P. H. Zeggelink. 1996. "Is Politics Power or Policy Oriented? A Comparative Analysis of Dynamic Access Models in Policy Networks." Journal of Mathematical Sociology 21: 77-111.

Streeck, Wolfgang, and Philippe C. Schmitter. 1985. "Community, Market, State - and Associations? The Prospective Contribution of Interest Governance to Social Order." European Sociological Review 1: 119-138.

van Waarden, Frans. 1992. "Dimensions and Types of Policy Networks." European Journal of Political Research 21: 29-52.

Vogel, David. 1987. National Styles of Regulation: Environmental Policy in Great Britain and the United States. Ithaca, NY: Cornell University Press.

Weible, Christopher M., and Paul A. Sabatier. 2005. "Comparing Policy Networks: Marine Protected Areas in California." Policy Studies Journal 33: 181-202.

Williamson, Oliver E. 1991. "Comparative Economic Organization: The Analysis of Discrete Structural Alternatives." Administrative Science Quarterly 36: 269-296.

Williamson, Oliver E. 2000. "The New Institutional Economics: Taking Stock, Looking Ahead." Journal of Economic Literature 38: 595-613.

Zafonte, Mathew, and Paul A. Sabatier. 1998. "Shared Beliefs and Imposed Interdependencies as Determinants of Ally Networks in Overlapping Subsystems." Journal of Theoretical Politics 10: 473-505. 


\title{
Supporting Information Online
}

\author{
Information Exchange in Policy Networks
}

\author{
Philip Leifeld Volker Schneider
}

\section{Summary statistics}

Table 1 shows summary statistics for the variables and relations used in the analysis.

\begin{tabular}{|c|c|c|c|c|c|c|c|}
\hline Term & Description & type & $\mathrm{N}$ & $\min$ & $\max$ & mean & $\mathrm{SD}$ \\
\hline$Y_{1}$ & $\begin{array}{l}\text { Political infor- } \\
\text { mation exchange }\end{array}$ & $\begin{array}{l}\text { binary, } \\
\text { directed }\end{array}$ & 870 & 0 & 1 & 0.39 & 0.49 \\
\hline$Y_{2}$ & $\begin{array}{l}\text { Technical infor- } \\
\text { mation exchange }\end{array}$ & $\begin{array}{l}\text { binary, } \\
\text { directed, } \\
\text { confirmed }\end{array}$ & 870 & 0 & 1 & 0.07 & 0.26 \\
\hline$C(y)$ & $\begin{array}{l}\text { Shared } \\
\text { committees }\end{array}$ & $\begin{array}{l}\text { valued, } \\
\text { undirected }\end{array}$ & 870 & 0 & 13 & 1.99 & 2.42 \\
\hline$I A(y)$ & $\begin{array}{l}\text { Influence } \\
\text { attribution }\end{array}$ & $\begin{array}{l}\text { binary, } \\
\text { directed }\end{array}$ & 870 & 0 & 1 & 0.32 & 0.47 \\
\hline$P S(y)$ & $\begin{array}{l}\text { Preference } \\
\text { similarity }\end{array}$ & $\begin{array}{l}\text { valued, } \\
\text { undirected }\end{array}$ & 870 & 0 & 4.9 & 2.42 & 1.14 \\
\hline$B C_{Y_{1}}(y)$ & $Y_{1}$ betweenness & nodal attribute & 30 & 0 & 125.10 & 19.30 & 29.73 \\
\hline$B C_{Y_{2}}(y)$ & $Y_{2}$ betweenness & nodal attribute & 30 & 0 & 109.90 & 18.00 & 29.90 \\
\hline & $\begin{array}{l}\text { Type of } \\
\text { organization }\end{array}$ & $\begin{array}{l}\text { nodal attribute, } \\
\text { categorical }\end{array}$ & 30 & \multicolumn{4}{|c|}{11 gov, 7 ig, 3 io, 3 par, 6 sci } \\
\hline
\end{tabular}

Table 1: Summary statistics

\section{Alternative model specifications}

\begin{tabular}{llcccc}
\hline & & \multicolumn{2}{c}{ Political information } & \multicolumn{2}{c}{ Technical information } \\
& & Model 5 & Model 6 & Model 7 & Model 8 \\
\hline$L(y)$ & Edges & $-3.78^{* * *}$ & $-3.62^{* * *}$ & $-4.32^{* * *}$ & $-6.49^{* * *}$ \\
& & $(0.17)$ & $(0.17)$ & $(0.29)$ & $(0.34)$ \\
$P S(y)$ & Preference similarity & 0.10 & 0.12 & -0.07 & 0.13 \\
& & $(0.06)$ & $(0.07)$ & $(0.10)$ & $(0.13)$ \\
$I F_{\text {gov }}(y)$ & Governmental alter & $0.58^{* * *}$ & $0.50^{* * *}$ & $0.64^{* * *}$ & $0.41^{* * *}$ \\
& & $(0.06)$ & $(0.06)$ & $(0.07)$ & $(0.10)$ \\
\multirow{2}{*}{$F_{\text {sci }}(y)$} & Scientific ego & $0.35^{* * *}$ & 0.08 & $1.58^{* * *}$ & $1.48^{* * *}$
\end{tabular}




\begin{tabular}{|c|c|c|c|c|c|}
\hline & & Model 5 & Model 6 & Model 7 & Model 8 \\
\hline & & $(0.08)$ & $(0.08)$ & $(0.11)$ & $(0.12)$ \\
\hline \multirow[t]{2}{*}{$C(y)$} & Common committees & $0.33^{* * *}$ & $0.29^{* * *}$ & $0.23^{* * *}$ & $0.17^{* * *}$ \\
\hline & & $(0.01)$ & $(0.02)$ & $(0.01)$ & $(0.01)$ \\
\hline \multirow[t]{2}{*}{$O(y)$} & Scientific communication & & $3.48^{* * *}$ & & $2.97^{* * *}$ \\
\hline & & & $(0.42)$ & & $(0.07)$ \\
\hline \multirow{2}{*}{$U_{i g}(y)$} & Interest group homophily & $1.22^{* * *}$ & $1.16^{* * *}$ & $1.32^{* * *}$ & $1.16^{* * *}$ \\
\hline & & $(0.11)$ & $(0.12)$ & $(0.33)$ & $(0.28)$ \\
\hline \multirow[t]{2}{*}{$I A(y)$} & Influence attribution & $0.88^{* * *}$ & $0.80^{* * *}$ & $0.65^{* * *}$ & $0.38^{* * *}$ \\
\hline & & $(0.06)$ & $(0.06)$ & $(0.07)$ & $(0.10)$ \\
\hline \multirow[t]{2}{*}{$v\left(y, \theta_{1}\right)$} & GWESP & $1.33^{* * *}$ & $1.26^{* * *}$ & $0.51^{* * *}$ & $0.37^{* * *}$ \\
\hline & & $(0.02)$ & $(0.03)$ & $(0.05)$ & $(0.05)$ \\
\hline \multirow[t]{2}{*}{$w\left(y, \theta_{2}\right)$} & GWDSP & $-0.16^{* * *}$ & $-0.16^{* * *}$ & $-0.23^{* * *}$ & $-0.34^{* * *}$ \\
\hline & & $(0.01)$ & $(0.02)$ & $(0.02)$ & $(0.03)$ \\
\hline \multirow[t]{2}{*}{$R(y)$} & Reciprocity & $0.98^{* * *}$ & $0.82^{* * *}$ & $2.15^{* * *}$ & $1.72^{* * *}$ \\
\hline & & $(0.06)$ & $(0.07)$ & $(0.15)$ & $(0.15)$ \\
\hline \multirow[t]{5}{*}{$B C(y)$} & Betweenness Centrality & & $0.00^{*}$ & & $0.02^{* * *}$ \\
\hline & & & $(0.00)$ & & $(0.00)$ \\
\hline & AIC & 890.26 & 856.46 & 354.93 & 307.44 \\
\hline & $\mathrm{BIC}$ & 937.94 & 913.68 & 402.61 & 364.66 \\
\hline & Log Likelihood & -435.13 & -416.23 & -167.46 & -141.72 \\
\hline
\end{tabular}

MCMC MLE. ${ }^{* * *} p<0.001,{ }^{* *} p<0.01,{ }^{*} p<0.05,{ }^{\circ} p<0.1$

Table 2: Exponential random graph model

Alternative model specifications 5 and 8 show that omitting other communication channels (as a relational opportunity structure) largely leaves the predictions unaffected. Models 6 and 9 show how the betweenness centrality of alter, $B C(y)$, influences the choice of peers compared to models 2 and 4 . The effect is significant but small and does not improve the model fit to a large extent.

Four other models have been tested but are not reported in table 2. First, including a transitivity term does not affect the results of model 4, but it significantly decreases the goodness of fit regarding model 2. Transitive triads work as a partial substitute for the shared partner distributions GWESP and GWDSP; including the former makes the latter insignificant and vice-versa, but a shared partner distribution with a geometric decay parameter is better at capturing information flows. Second, as another variation of models 2 and 4, an interest group outfactor dummy variable was added to correct for the potential bias that may arise in the interest group homophily term if interest groups establish more links than other actors in general. Adding this control variable does not alter the models significantly.

\section{List of actors involved}

\begin{tabular}{lll}
\hline Code & Name & Type \\
\hline BMA & Federal Ministry for Labor and Social Affairs & Government
\end{tabular}




\begin{tabular}{|c|c|c|}
\hline Code & Name & Type \\
\hline BML & Federal Ministry for Food, Agriculture and Forestry & Government \\
\hline BMI & Federal Ministry of the Interior & Government \\
\hline BMJ & Federal Ministry for Youth, Family and Health & Government \\
\hline BMW & Federal Ministry of Economics and Finance & Government \\
\hline BMT & Federal Ministry for Research and Technology & Government \\
\hline $\mathrm{BBA}$ & $\begin{array}{l}\text { Federal Biological Research Centre for Agriculture and } \\
\text { Forestry }\end{array}$ & Government \\
\hline BAM & Federal Institute for Materials Research and Testing & Government \\
\hline $\mathrm{BAU}$ & $\begin{array}{l}\text { Federal Institute for Occupational Safety and Accident Re- } \\
\text { search }\end{array}$ & Government \\
\hline BGA & Federal Health Office & Government \\
\hline UBA & Federal Environment Agency & Government \\
\hline SPD & Social Democratic Party of Germany & Political party \\
\hline CDU & Christian-Democratic Union of Germany & Political party \\
\hline FDP & Free Democratic Party & Political party \\
\hline AGV & Consumers' Working Group & Interest group \\
\hline BUND & Friends of the Earth Germany & Interest group \\
\hline VCI & German Chemical Industry Association & Interest group \\
\hline $\mathrm{BBU}$ & $\begin{array}{l}\text { Federal Association of Citizens' Initiatives for Environ- } \\
\text { mental Protection }\end{array}$ & Interest group \\
\hline IHT & $\begin{array}{l}\text { Association of German Chambers of Industry and Com- } \\
\text { merce }\end{array}$ & Interest group \\
\hline VAA & $\begin{array}{l}\text { Association of Employed Academics and Executives in the } \\
\text { Chemical Industry }\end{array}$ & Interest group \\
\hline IGC & Chemical, Paper and Ceramic Industrial Union & Interest group \\
\hline $\mathrm{BGC}$ & Professional Society of the Chemical Industry & Science \& Technology \\
\hline DFG & German Research Foundation & Science \& Technology \\
\hline $\mathrm{SRU}$ & German Advisory Council on the Environment & Science \& Technology \\
\hline VDB & German Company Doctors' Association & Science \& Technology \\
\hline GDC & German Chemical Society & Science \& Technology \\
\hline GSF & German Association of Radiation Research & Science \& Technology \\
\hline $\mathrm{EC}$ & European Community & International Organization \\
\hline OECD & Organisation for Economic Co-operation and Development & International Organization \\
\hline $\mathrm{CEF}$ & European Chemical Industry Council & International Organization \\
\hline
\end{tabular}

\section{List of policy committees}

\begin{tabular}{|c|c|c|c|}
\hline Code & Name & Areas and levels & Function \\
\hline IPU & $\begin{array}{l}\text { Interadministrative Project } \\
\text { Group Environmental Chemicals }\end{array}$ & Administration & $\begin{array}{l}\text { Policy } \\
\text { Formulation }\end{array}$ \\
\hline BLAU & $\begin{array}{l}\text { Intergovernmental Committee } \\
\text { Environmental Chemicals }\end{array}$ & $\begin{array}{l}\text { Federal States } \\
\text { (Bundesländer) }\end{array}$ & $\begin{array}{l}\text { Policy } \\
\text { Formulation }\end{array}$ \\
\hline
\end{tabular}




\begin{tabular}{|c|c|c|c|}
\hline Code & Name & Areas and levels & Function \\
\hline $\mathrm{AGU}$ & $\begin{array}{l}\text { Working Group on Environmen- } \\
\text { tal Affairs }\end{array}$ & Interest Groups & $\begin{array}{l}\text { Policy } \\
\text { Formulation }\end{array}$ \\
\hline DFG.ENV & $\begin{array}{l}\text { Working Group of the German } \\
\text { Research Foundation on Environ- } \\
\text { mental Chemicals }\end{array}$ & Science & $\begin{array}{l}\text { Policy } \\
\text { Formulation }\end{array}$ \\
\hline DFG.MAK & $\begin{array}{l}\text { Working Group of the German } \\
\text { Research Foundation on Toxic } \\
\text { Substances at the Workplace }\end{array}$ & Science & $\begin{array}{l}\text { Policy } \\
\text { Formulation }\end{array}$ \\
\hline BMA.AGA & $\begin{array}{l}\text { Committee on Toxic Substances } \\
\text { at the Workplace }\end{array}$ & Administration & $\begin{array}{l}\text { Policy } \\
\text { Formulation }\end{array}$ \\
\hline BGA.AC & $\begin{array}{l}\text { Ad hoc Groups Chemcials Law at } \\
\text { the Federal Health Office }\end{array}$ & Administration & $\begin{array}{l}\text { Policy } \\
\text { Formulation }\end{array}$ \\
\hline BMI.ST & $\begin{array}{l}\text { Working Group of the Ministry of } \\
\text { the Interior on Toxic Substances } \\
\text { in Water }\end{array}$ & Administration & $\begin{array}{l}\text { Policy } \\
\text { Formulation }\end{array}$ \\
\hline BMG.BIO & $\begin{array}{l}\text { Project Group Environmental } \\
\text { Chemicals and Biocides }\end{array}$ & Administration & $\begin{array}{l}\text { Policy } \\
\text { Formulation }\end{array}$ \\
\hline IMA.CHEM & $\begin{array}{ll}\text { Interadministrative } & \text { Working } \\
\text { Group Chemicals Law } & \end{array}$ & Administration & $\begin{array}{l}\text { Policy } \\
\text { Formulation }\end{array}$ \\
\hline UBA.AG & $\begin{array}{l}\text { Ad hoc Groups Chemcials Law at } \\
\text { the Federal Office for the Envi- } \\
\text { ronment }\end{array}$ & Administration & $\begin{array}{l}\text { Policy } \\
\text { Formulation }\end{array}$ \\
\hline BMT.AC & $\begin{array}{l}\text { Expert Groups on Toxic Sub- } \\
\text { stances at the Workplace at the } \\
\text { Ministry of Research }\end{array}$ & Science & $\begin{array}{l}\text { Policy } \\
\text { Formulation }\end{array}$ \\
\hline OECD.CP & $\begin{array}{l}\text { OECD Working Groups Chemi- } \\
\text { cals Programme }\end{array}$ & OECD & $\begin{array}{l}\text { Policy } \\
\text { Formulation }\end{array}$ \\
\hline EU.WG & $\begin{array}{l}\text { EU Working Group Classification } \\
\text { of Dangerous Substances }\end{array}$ & $\begin{array}{l}\text { European } \\
\text { Union }\end{array}$ & $\begin{array}{l}\text { Policy } \\
\text { Formulation }\end{array}$ \\
\hline EU.COR & $\begin{array}{l}\text { EU Expert Group } 6^{\text {th }} \text { Amend- } \\
\text { ment of the Dangerous Substance } \\
\text { Directive }\end{array}$ & $\begin{array}{l}\text { European } \\
\text { Union }\end{array}$ & $\begin{array}{l}\text { Policy } \\
\text { Formulation }\end{array}$ \\
\hline GDC.OS & $\begin{array}{l}\text { Expert Group Environmentally } \\
\text { Relevant Old Chemicals }\end{array}$ & Administration & $\begin{array}{l}\text { Policy } \\
\text { Implementation }\end{array}$ \\
\hline BGC.AC & $\begin{array}{l}\text { Committee on Health Damages } \\
\text { by Old Chemicals }\end{array}$ & Administration & $\begin{array}{l}\text { Policy } \\
\text { Implementation }\end{array}$ \\
\hline AC.NS & $\begin{array}{l}\text { Expert Committee New Chemi- } \\
\text { cals }\end{array}$ & Administration & $\begin{array}{l}\text { Policy } \\
\text { Implementation }\end{array}$ \\
\hline CC.OS & $\begin{array}{l}\text { Coordination Committee Old } \\
\text { Chemicals }\end{array}$ & Administration & $\begin{array}{l}\text { Policy } \\
\text { Implementation }\end{array}$ \\
\hline EU.APP & $\begin{array}{l}\text { Expert Groups for Implementa- } \\
\text { tion of the } 6^{\text {th }} \text { Amendment Direc- } \\
\text { tive }\end{array}$ & $\begin{array}{l}\text { European } \\
\text { Union }\end{array}$ & $\begin{array}{l}\text { Policy } \\
\text { Implementation }\end{array}$ \\
\hline
\end{tabular}

Table 4: Institutionalized policy committees (source: Schneider 1988: 145) 


\section{R source code}

Note: An updated replication script, which is compatible with more recent software versions, is available in the xergm package for $\mathrm{R}$. The package also contains the dataset.

\# This is a script for the statistical programming environment $R$.

\# R can be obtained from: http://www.r-project.org

\# Please install the packages 'statnet' and 'coda' before proceeding!

\# The .csv files can be found at: http://hdl.handle.net/1902.1/17004

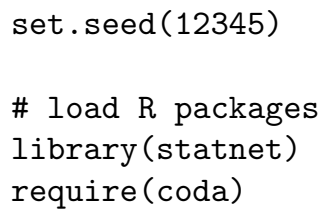


prefsim <- dist (intpos, method="euclidean", diag=F, upper=T) \# equation 2 prefsim <- $\max ($ prefsim) - prefsim \# equation 3

prefsim <- as.matrix (prefsim)

committee <- crossprod(as.matrix(comm), as.matrix(comm)) \# equation 4

diag(committee) <- 0 \# the diagonal has no meaning

types <- as.character (types [,1]) \# convert to character vector

pol <- as.matrix(pol) \# convert to matrix object

infrep <- as.matrix(infrep) \# convert to matrix object

\# convert matrices to networks and attach attributes to them

nw.infrep <- network(infrep) \# mutual influence attribution

set.vertex.attribute(nw.infrep, "orgtype", types)

nw.pol <- network(pol) \# political/stratgic information exchange

set.vertex.attribute(nw.pol, "orgtype", types)

set.vertex.attribute(nw.pol, "betweenness", betweenness(nw.pol)) \# centrality

nw.sci <- network(sci) \# confirmed and directed technical information exchange set.vertex.attribute(nw.sci, "orgtype", types)

set.vertex.attribute(nw.sci, "betweenness", betweenness(nw.sci)) \# centrality

nw.committee <- network (committee, directed=FALSE) \# no. of common committees

set.vertex.attribute(nw.committee, "orgtype", types)

set.edge.value (nw.committee, "weight", committee)

nw.intpos <- network(prefsim, directed=FALSE) \# similarity in interest positions set.vertex.attribute(nw.intpos, "orgtype", types)

set.edge.value (nw.intpos, "weight", prefsim)

\section{\#\#\#\#\#\#\#\#\# ESTIMATION OF ERGMS \#\#\#\#\#\#\#\#\#}

\# ERGM: political/strategic information exchange; only preference similarity model1 <- ergm(nw.pol edges + edgecov(nw.intpos, "weight"),

eval.loglik=TRUE, check.degeneracy=TRUE, seed=12345)

sink(file="model1.txt") \# this output file contains coefficients

print (summary (model1))

print(model1\$mle.lik) \# also print the log likelihood

$\operatorname{sink}()$

\# ERGM: political/strategic information exchange; complete model

model2 <- ergm(nw.pol edges + edgecov(nw.intpos, "weight") + mutual +

nodemix ("orgtype", base $=-7$ ) + nodeifactor ("orgtype", base $=-1$ ) +

nodeofactor("orgtype", base = -5) + edgecov(nw.committee, "weight") +

$\operatorname{edgecov}(n w . s c i)+\operatorname{edgecov}(n w . i n f r e p)+\operatorname{gwesp}(0.1$, fixed $=$ TRUE $)+$

gwdsp $(0.1$, fixed = TRUE), eval.loglik=TRUE, check.degeneracy=TRUE, seed $=12345)$

sink(file="model2.txt") \# this output file contains coefficients

print (summary (model2))

print(model2\$mle.lik) \# also print the log likelihood

$\operatorname{sink}()$

\# ERGM: technical/scientific information exchange; only preference similarity

model3 <- ergm(nw.sci edges + edgecov(nw.intpos, "weight"),

eval. loglik=TRUE, check. degeneracy=TRUE, seed=12345)

sink(file="model3.txt") \# this output file contains coefficients

print (summary (model3))

print(model3\$mle.lik) \# also print the log likelihood 
$\operatorname{sink}()$

\# ERGM: technical/scientific information exchange; complete model model 4 <- ergm(nw.sci edges + edgecov(nw.intpos, "weight") + mutual + nodemix ("orgtype", base $=-7$ ) + nodeifactor ("orgtype", base $=-1$ ) + nodeofactor ("orgtype", base $=-5$ ) + edgecov(nw.committee, "weight") + $\operatorname{edgecov}(n w . p o l)+\operatorname{edgecov}(n w . i n f r e p)+\operatorname{gwesp}(0.1$, fixed $=$ TRUE $)+$ gwdsp $(0.1$, fixed = TRUE), eval.loglik=TRUE, check.degeneracy=TRUE, seed=12345)

sink(file="model4.txt") \# this output file contains coefficients print (summary (model4))

print(model4\$mle.lik) \# also print the log likelihood sink ()

\# ERGM: like model 2, but without the other communication (validity check) model5 <- ergm(nw.pol edges + edgecov(nw.intpos, "weight") + mutual + nodemix ("orgtype", base $=-7$ ) + nodeifactor ("orgtype", base $=-1$ ) + nodeofactor ("orgtype", base $=-5$ ) + edgecov(nw.committee, "weight") + edgecov(nw.infrep) + gwesp $(0.1$, fixed $=$ TRUE $)+$

gwdsp (0.1, fixed = TRUE), eval.loglik=TRUE, check.degeneracy=TRUE, seed $=12345)$

sink(file="model5.txt") \# this output file contains coefficients print (summary (model5))

print(model5\$mle.lik) \# also print the log likelihood $\operatorname{sink}()$

\# ERGM: like model 2, but with betwenness centrality as covariate of alter model6 <- ergm(nw.pol edges + edgecov(nw.intpos, "weight") + mutual + nodemix ("orgtype", base $=-7$ ) + nodeifactor ("orgtype", base = -1) + nodeofactor ("orgtype", base = -5) + edgecov(nw.committee, "weight") + edgecov(nw.sci) + edgecov(nw.infrep) $+\operatorname{gwesp}(0.1$, fixed $=$ TRUE $)+$ $\operatorname{gwdsp}(0.1$, fixed $=$ TRUE) + nodeicov("betweenness"), eval.loglik=TRUE, check. degeneracy=TRUE, seed=12345)

sink(file="model6.txt") \# this output file contains coefficients print (summary (model6))

print(model6\$mle.lik) \# also print the log likelihood sink ()

\# ERGM: like model 4, but without the other communication (validity check) model7 <- ergm(nw.sci edges + edgecov(nw.intpos, "weight") + mutual + nodemix ("orgtype", base $=-7$ ) + nodeifactor ("orgtype", base $=-1$ ) + nodeofactor ("orgtype", base $=-5)+$ edgecov(nw.committee, "weight") + edgecov(nw.infrep) + gwesp(0.1, fixed = TRUE) + gwdsp (0.1, fixed = TRUE), eval.loglik=TRUE, check.degeneracy=TRUE, seed $=12345)$

sink(file="model7.txt") \# this output file contains coefficients print (summary (model7))

print(model7\$mle.lik) \# also print the log likelihood $\operatorname{sink}()$

\# ERGM: like model 4, but with betwenness centrality as covariate of alter model8 <- ergm(nw.sci edges + edgecov(nw.intpos, "weight") + mutual + nodemix ("orgtype", base $=-7$ ) + nodeifactor ("orgtype", base $=-1$ ) + nodeofactor ("orgtype", base = -5) + edgecov(nw.committee, "weight") + edgecov(nw.pol) $+\operatorname{edgecov}(n w . i n f r e p)+\operatorname{gwesp}(0.1$, fixed $=$ TRUE $)+$ gwdsp $(0.1$, fixed = TRUE) + nodeicov("betweenness"), eval.loglik=TRUE, check. degeneracy=TRUE, seed=12345)

sink(file="model8.txt") \# this output file contains coefficients 


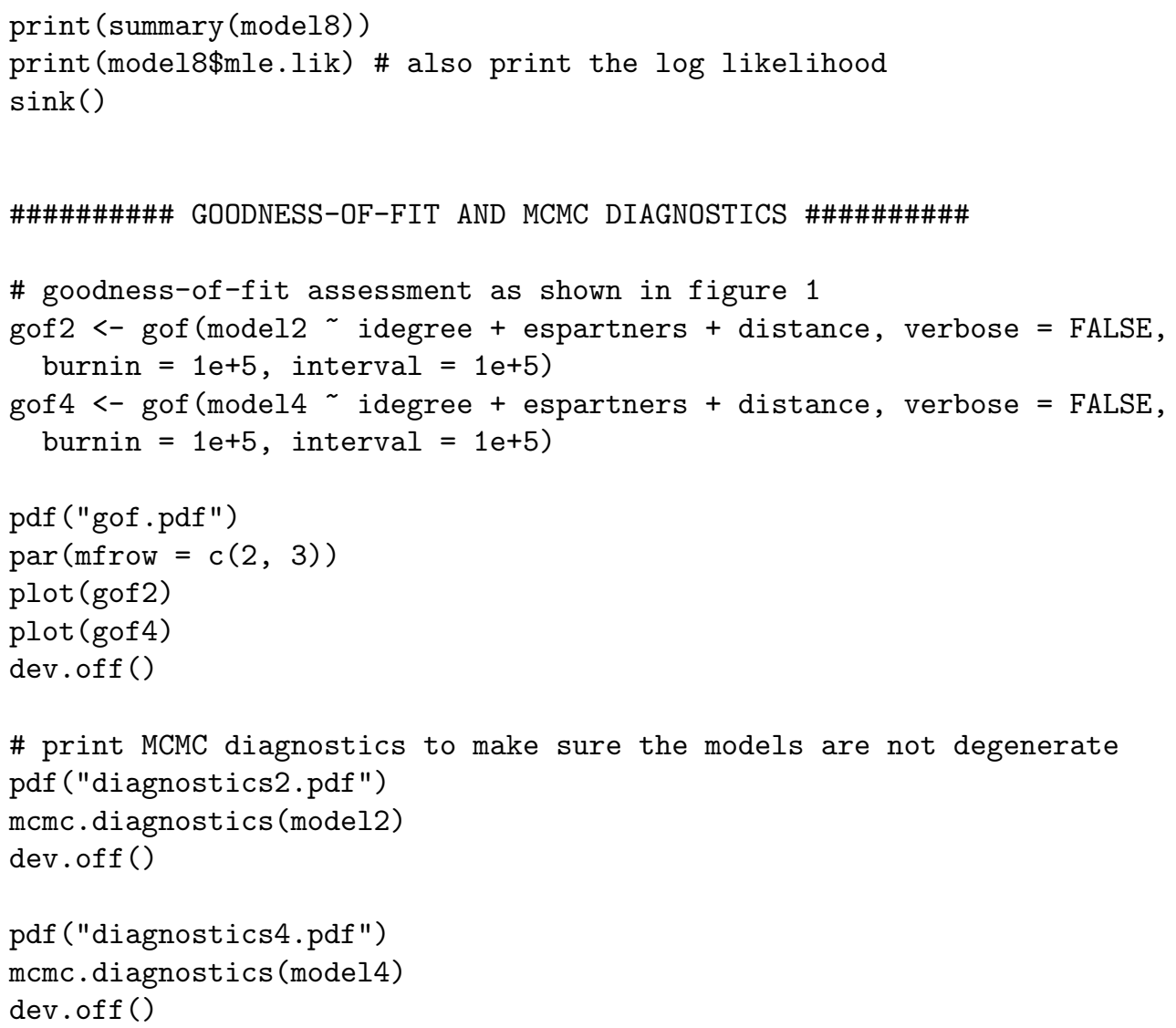

\section{References}

Schneider, Volker. 1988. Politiknetzwerke der Chemikalienkontrolle: Eine Analyse einer transnationalen Politikentwicklung. New York/Berlin: de Gruyter.

Schneider, Volker, and Philip Leifeld. 2009. "Überzeugungssysteme, Diskursnetzwerke und politische Kommunikation: Ein zweiter Blick auf die deutsche Chemikalienkontrolle der 1980er Jahre." In Politiknetzwerke. Modelle, Anwendungen und Visualisierungen, eds. Volker Schneider, Frank Janning, Philip Leifeld, and Thomas Malang. Wiesbaden: VS Verlag für Sozialwissenschaften, 139-158. 